\title{
Diagnosis and Management of Elder Abuse by Family Physician
}

\author{
Virginie Dumortier1, Humbert de Freminville ${ }^{1,2 *}$ \\ ${ }^{1}$ General Practitioner Department, University of Lyon 1, Lyon, France \\ 2Laboratoire "Santé, Individu, Société" - EAM 4128, Faculté de Médecine Laënnec 7-11 rue Guillaume Paradin, \\ Lyon, France \\ Email: virginiedfr@yahoo.fr, ${ }^{*}$ humbert.de-freminville@univ-lyon1.fr
}

Received 7 April 2014; revised 11 May 2014; accepted 18 May 2014

Copyright (C) 2014 by authors and Scientific Research Publishing Inc. This work is licensed under the Creative Commons Attribution International License (CC BY). http://creativecommons.org/licenses/by/4.0/

\section{(c) (i) Open Access}

\section{Abstract}

The purpose of this study is to investigate the difficulties encountered by primary care physicians in diagnosing and handling elderly abuse. A survey of the practice of 266 family physicians in France was conducted by email using a questionnaire during the fall of 2012 . Statistical analysis was performed using a Chi-2 test for the comparison of two qualitative variables, and the Kruskal-Wallis test was used to compare a qualitative variable with an ordinal one. 77 physicians responded to the questionnaire. They are often faced with the phenomenon of mistreatment, including psychological abuse, of elderly people. They describe the diagnosis correctly but express management difficulties. These difficulties are due to lack of knowledge of the law and a lack of practical tools usable on a daily basis. These physicians call for better training regarding the law and clearer reporting procedures. Education and training in the legislative field must be improved. This conclusion has been reached before in previous surveys in the USA and Europe since the 1970s, which leads to the question as to whether full comprehension of the magnitude of the issue exists. Perhaps the complexity of medical practice requires that an anthropological approach should be taken to identify all the facets involved.

\section{Keywords}

Primary Care, Law, Medicine, Elder Abuse

\section{Introduction}

Elder abuse is a phenomenon that has been taken into account since the late twentieth century. The concept was first described in the British Medical Journal in 1975 under the term "granny battering” [1] [2]. The first research on the abuse of elderly people in developed countries started in the 1980s. Data and facts reported in

${ }^{*}$ Corresponding author. 
some developing countries show that it is a universal phenomenon [3]. Studies in the 1990s revealed prevalence rates ranging from 1.3 [4]-[7] to 32.8 percent [8]. Abuse is a reason for concern because the number of elderly will increase dramatically. By 2025, the global population aged 60 and over will have more than doubled [9].

Abuse is an elusive concept sometimes difficult to detect due to the many forms it can take. International studies show that our knowledge of the issue is unclear and abuse can only be approached through a comprehensive assessment of often complex situations [10]. Health professionals are often faced with the suspicion of abuse for which they must make an assessment or call on a competent authority to make one. Physical abuse is more easily objectified but neglect, sexual abuse and other problems of violence are rarely identified. The field of psychological abuse is even more difficult to explore. It is a sensitive issue difficult to objectify because of its quasiintangibility.

Health professionals rarely report cases of abuse [11]-[13]. Multidisciplinary management is of great interest and collaboration with the attending physician, the coroner, the nursing home, and social and geriatric services should be preferred. The family physician occupies a central place in this framework and may be the sole point of contact available to caregivers who come across a situation of abuse. A qualitative survey in the USA (Rodriguez MA et al., 2006) revealed 3 paradoxes expressed by physicians about mandatory reporting: the paradox of physician-patient rapport, the paradox of patient quality of life and the paradox of physician control [14].

This study was conducted among family physicians in the Rhône-Alpes region in France, a region in which nearly $10 \%$ of the French metropolitan population live. The hypothesis is that physicians find it difficult to diagnose and manage cases of abuse, particularly in terms of reporting. This work evaluates their professional practices in view to improving understanding of their difficulties. The purpose of this study is to investigate the difficulties encountered by primary care physicians in diagnosing and handling elderly abuse.

\section{Materials and Methods}

\subsection{Settings and Participants}

The study involved 266 primary care physicians in the Rhône-Alpes area, 224 of whom were training physicians associated with the Department of General Medicine at the University Claude Bernard Lyon 1. Mean age and age range of the participants was not required, but instead beginning of practice.

\subsubsection{Criteria}

Inclusion criteria: work as a self-employed physician in general medical practice.

Exclusion criteria: employee physician in the private and public sector.

\subsubsection{Ethical Committee}

This survey did not require approval from an ethical committee in France (L 1121-1 of the French Public Health Code) and conformed to French professional practice (R 4127 of the French Public Health Code).

\subsection{The Method}

\subsubsection{Data Collection}

An email was sent to the physicians in November 2012, and the responses were obtained 15 days later. This email explained the purpose of the survey and contained an electronic link to the anonymous questionnaire if the physician wanted to participate (Appendix). The survey was closed on November 30 ${ }^{\text {th }}, 2012$.

\subsubsection{Data Analysis}

Data analysis was performed online on the website biosta TGV of the University of Paris, France [15]. We compared two qualitative variables with the Chi-2 test (theoretical numbers $\geq 5$ ), the Yates test (theoretical numbers $<5$ ), and the Fisher test (theoretical numbers $<3$ ). The Kruskal-Wallis test (Table 1, Table 2) was used to compare qualitative variables ( $>2$ groups) with an ordinal variable.

\section{Results}

\subsection{Ratio, Knowledge and Medical Practice}

77 questionnaires (28.9\%) were completed. 15 email addresses were wrong. Sex ratio was $69 \%$ men and 31\% 
women (question 1). $48 \%$ of physicians had less than $25 \%$ patients aged over 65 , $43 \%$ between 25 and 50, 8\% between 50 and $75,1 \%$ over 75 (question 5).

Recognition of clinical signs of abuse (question 6 ) was given a score of 1 (i.e. very bad) by $12 \%$ of doctors, 2 by $40 \%$ (i.e. bad), 3 by $45 \%$ (i.e. good), and 4 by $3 \%$ (i.e. very good). Knowledge of legislation on elder abuse (question 8) was given a score of 1 by $34 \%, 2$ by $40 \%, 3$ by $22 \%$, and 4 by $4 \% .55 \%$ of the physicians who suspected cases of abuse had not reported, 24\% had reported once, 19\% had reported between 1 to 5 times, and 2\% had reported more than 5 times (question 10). 30\% of the physicians suspected physical abuse, 83\% suspected psychological abuse, $60 \%$ suspected neglect, $5 \%$ suspected sexual abuse. $11 \%$ of the physicians suspected another type of abuse (question 11): financial embezzlement, theft, racketeering, various attacks, threats, theft.

When the physician is confronted by a problem (question 13), 83\% used dialogue with relatives and / or caregivers. $41 \%$ used the hospital for the elderly to avoid risk. $24 \%$ used reporting (administrative or judicial), $13 \%$ used an institution (College of Physicians and associations). To help doctors perform reporting correctly (question 15 ), $61 \%$ of the physicians required clear channels, $57 \%$ better training, $40 \%$ required contacts to open dialogue, $44 \%$ better information, $19 \%$ of physicians are sure of acting without fear of repercussions.

\subsection{Physician Gender, Location and Physical or Psychological Elder Abuse}

There was a significant relationship (Fisher Test, $\alpha=5 \%$ ) between suspected abuse and gender ( $\mathrm{p}=0.001$ ), and between knowledge of signs of psychological abuse and violence (Kruskal-Wallis test, $\alpha=5 \%)(\mathrm{p}=0.001)$. There was no significant relationship (Kruskal-Wallis test, $\alpha=5 \%$ ) between recognition of clinical signs of abuse and geographical practice $(\mathrm{p}=0.44)$ (Table 1$)$, beginning of practice $(\mathrm{p}=0.89)$ or percent of the elderly over 65 years old $(\mathrm{p}=0.28)$. Nor was there a significant relationship (Kruskal-Wallis test, $\alpha=5 \%$ ) between recognition of clinical signs of psychological abuse and geographical practice $(\mathrm{p}=0.20)$, beginning of practice ( $\mathrm{p}$ $=0.28)$ or percent of the elderly over 65 years old $(p=0.19)$.

\subsection{Suspected Abuse}

There was no significant relationship (Fisher Test, $\alpha=5 \%$ ) between suspected abuse and location (p $=0.22$ ), beginning of practice $(\mathrm{p}=0.56)$, individual or not $(\mathrm{p}=0.91)$, or percent of the elderly over 65 years old $(\mathrm{p}=0.06)$. There was a significant relationship (Fisher Test, $\alpha=5 \%)$ between suspected abuse and reporting $(\mathrm{p}=3.14 \times$ $10^{-5}$ ), and between knowledge of clinical signs and suspected abuse (Kruskal-Wallis test, $\left.\alpha=5 \%\right)(\mathrm{p}=0.007)$.

\subsection{Knowledge of Legislation on Elder Abuse}

There was no significant relationship (Kruskal-Wallis test, $\alpha=5 \%$ ) between knowledge of legislation on abuse and geographical practice $(p=0.65)$, beginning of practice $(p=0.31)$ or percent of the elderly over 65 years old $(\mathrm{p}=0.20)$, but there was a significant relationship (Kruskal-Wallis test, $\alpha=5 \%$ ) between reporting and knowledge of the legislation on elder abuse $\left(\mathrm{p}=2.96 \times 10^{-5}\right)$ (Table 2).

\section{Discussion}

\subsection{Main Findings of This Study}

The main goal of our investigation was to determine whether primary care physicians encountered difficulties regarding the diagnosis of situations of abuse towards a person. According to the results, they did not seem to

Table 1. The Recognition of clinical signs of elder abuse and the location of physicians.

\begin{tabular}{|c|c|c|c|c|c|c|}
\hline & & \multicolumn{4}{|c|}{ Recognition of clinical signs of elder abuse } & \\
\hline & & 1 & 2 & 3 & 4 & \\
\hline \multirow{4}{*}{ Location } & Rural & 0 & 7 & 7 & 1 & 15 \\
\hline & Suburban & 3 & 11 & 15 & 0 & 29 \\
\hline & Urban & 6 & 13 & 13 & 1 & 33 \\
\hline & & 9 & 31 & 35 & 2 & 77 \\
\hline
\end{tabular}

Kruskal-Wallis Test, $\alpha=5 \%, \mathrm{p}=0.44$. 
Table 2. The mandatory reporting and knowledge of the legislation on elder abuse.

\begin{tabular}{ccccccc}
\hline & & \multicolumn{4}{c}{ Knowledge of the legislation } \\
\cline { 3 - 6 } & & 1 & 2 & 3 & 4 & \\
\hline \multirow{3}{*}{ Mendatory } & Never & 13 & 19 & 3 & 0 & 35 \\
reporting & once & 5 & 5 & 4 & 1 & 15 \\
& 1 to 5 times & 1 & 1 & 1 & 2 & 12 \\
& More than 5 times & 0 & 25 & 16 & 3 & 63 \\
\hline
\end{tabular}

Kruskal-Wallis Test, $\alpha=5 \%, \mathrm{p}=2.96 \times 10^{-5}$.

ignore the clinical signs permitting the detection of a situation of abuse. The majority of respondents gave a rating of 3 (good) to their recognition of these signs. It is interesting to note that we obtained the same results with regard to the recognition of clinical signs of emotional abuse. $74 \%$ of respondents gave exactly the same answer to both questions.

Diagnosis of this type of abuse does not seem to be more difficult than other types since the majority of physicians gave a rating of 3 (good) to their ability to recognize such signs. We could have expected different results, since we saw that emotional abuse is more difficult to diagnose due to the lack of objectively measurable clinical signs, as opposed to physical abuse. For the majority of the respondents, knowledge of legislation on elder abuse obtained a score of 2 (bad), and even 1 (very poor), the latter score being given by more than a third of them. There is no legal definition of abuse, including elder abuse, in France.

However, the law does protect people who are inherently vulnerable, such as the elderly. This protection is first provided by civil law, which establishes a different legal status for vulnerable people and measures to protect them are implemented through the judicial system. In criminal law, the vulnerability of victims has major legal implications, since it is considered as an aggravating circumstance when the author cannot ignore it and may be a specific offense. French law punishes criminal acts while the French equivalent of the College of Physicians can take sanctions against those who abstain voluntarily from assisting a person in danger, thus physicians are increasingly subject to complaints based on this legal concept. It is unfortunate, if not surprising, that physicians are not more aware of the legislation, especially as the law is intended to protect people who report such cases, thus they undermine a position of privilege. One out of every two doctors runs the risk of their liability being challenged at least once in their professional life. However, their chances of criminal prosecution remain low, and in no way match "the fear of trial” felt by many practitioners. Understanding of the procedures and the real issues (avoidance of prosecution) could defuse this fear.

The results are consistent with those of international studies in which the data suggests that elder abuse is relatively common, despite the variability of the data explained by the lack of precise definitions and diverse collection conditions. Only 14 out of 77 doctors never suspected maltreatment of an elderly person.

\subsubsection{Experience and Suspected Cases}

The results show that $82 \%$ of doctors have suspected one or more cases of maltreatment of people aged over 65 in their exercise, despite the fact that geriatrics is not the main activity of most of them. We saw that the statistical tests did not reveal any significant relationship between the percentage of patients and suspected cases of abuse. Experience does not seem to play a role in suspected cases of elder abuse, since there is no significant relationship between such abuse and the number of years of exercise.

\subsubsection{Knowledge of the Law and Reporting}

We note that 55\% of physicians who already suspected one or more cases of abuse had never reported it. This means that less than 1 in 2 cases of suspected abuse is officially reported. These results confirm those found in international studies that suggest that one out of 13 or 14 cases of abuse of all types is reported [16]. We think that general practitioners (GPs) hesitate to report cases of abuse. Statistical tests show that there is a significant relationship between reporting and knowledge of the law on elder abuse. From this, we can deduce that knowledge of the laws that govern situations of abuse facilitates reporting them. Clark-Daniels et al. suggest that physicians’ lack of familiarity with reporting laws may contribute to under-reporting abuse, while Brewer R.A. et al. and Salend E. et al. cast doubt on their effectiveness. US studies have examined the potential benefits of man- 
datory reporting of elder abuse and domestic violence. According to them, it would both protect the victim and relieve the general practitioner who has the heavy responsibility of deciding whether or not to report suspected cases of elder abuse [17]. Doctors may fear that the whole administrative machinery and/or legal proceedings that may result from reporting abuse could be difficult to control in the future.

For the relatives of the elderly, the report can be seen as an indictment of an individual, whether right or wrong. The doctor may also wish to avoid being seen as an informer. Addressing the issue of abuse during a consultation or a home visit also raises the fear of loss of the trusting relationship established between them and the patient's family. The doctor may fear a worsening of the situation or the breaking-off of links with the elderly person and their family due to the report. Some doctors believe that their diagnosis is too subjective and lacks "evidence". They may also think that a suggestive sign of abuse is not always synonymous with imminent danger, and seek alternatives to reporting.

In an American study [18], physicians cited the following reasons for not reporting a suspected case of abuse: refusal by the victims (23\%), lack of knowledge of reporting procedures (21\%), lack of knowledge of laws (10\%), and lack of evidence (44\%). Physician training in elder abuse can help to overcome these obstacles. Many doctors are not aware that members of the victim's family are most often the perpetrators of abuse. Some do not realize that bruising, frequently found in the lesions of the elderly, may be a sign of physical abuse. There is a significant relationship between suspicion of elder abuse and recognition of clinical signs, whether it is a case of general or psychological abuse. This may seem logical, since an abusive situation cannot be suspected if it is not recognized.

\subsubsection{Types of Abuse Suspected}

According to our survey, most of the types of suspected abuse in the private practice of the population studied fall within the framework of psychological abuse, followed by neglect and physical abuse.

Psychological abuse represents the most suspected type of abuse. It is also, as seen above, the least obvious type of abuse to diagnose. This may explain why only $45 \%$ of the doctors who indicated one or more suspected cases of abuse have transmitted one or more alerts. It is possible that the elements leading to a diagnostic of psychological abuse are more difficult to objectify, thus doctors tend not to report such cases. These results agree in part with certain international studies in which situations of neglect make up a significant share of reported cases (Garre-Olmo J. et al., 2009).

\subsubsection{Warning Signs}

Signs alerting doctors are represented mainly by the words or the attitude of the patient or relatives. These results may appear surprising since the elderly often feel reluctant to address this type of issue with health professionals. The victim may be afraid of "retaliation" and a worsening situation, abandonment or institutionalization, especially as the author of the abuse is usually someone close. Questioning relatives is always useful and indispensable in frequent cases where the patient suffers from cognitive impairment. We observed that most studies consider the cognitive impairment or dementia status of the elderly as a risk factor for abuse [19]. The words and the attitude of the patient and family provide a wealth of information: inconsistent explanations for traumatic injuries, the detection of significant delays between the occurrence of physical injury or illness and the demand for care are all elements evocative of abuse.

\subsubsection{Attitude toward the Problem}

In the case of suspected abuse, $83 \%$ of the physicians surveyed preferred to resort to dialogue with the families and/or caregivers of the victim rather than to a report. As mentioned earlier, the family physician often enjoys a relationship of trust with the patients and their families, making it all the more difficult to manage this kind of situation. Dialogue with them may be enough to appease some situations, leading to individualized management with adequate monitoring while avoiding the use of such reporting.

Hospitalization takes second place in the attitude of GPs when dealing with the problem of abuse. It allows the elderly to avoid danger if it is imminent or difficult to assess. It allows performing additional tests capable of corroborating the diagnosis of abuse, an often complex task. This also allows the doctor to perform their role with the patient and the immediate entourage without denouncing anyone. Hospitalization provides time for reflection and carrying out additional investigations to assist in decision-making, without engaging the patient and family in a specific way. 


\subsection{Bias}

Some bias may be noted. Males are overrepresented compared to females, according to official data on regional [20] and national [21] distribution. There was a selection bias in our sample. 84\% of physicians who received the questionnaire had a university teaching activity (tutor or lecturer), which is not representative of the general population of GPs in the Rhône-Alpes region. Physicians caring for few elderly persons were not excluded from the study.

\section{Conclusions}

Regardless of their experience, activity and areas of practice, physicians are faced with the phenomenon of abuse, especially in the form of psychological violence. The barriers to reporting are a lack of training, poor knowledge of the law, and a lack of clarity regarding mandatory reporting. Solutions can be implemented to remedy these barriers. The teaching programs of universities should be revamped to include this subject in their curricula.

This conclusion has been reached before in previous surveys in the USA and Europe since the 1970s, which leads to the question as to whether full comprehension of the magnitude of the issue exists. How could this status be explained? Perhaps the complexity of medical practice requires that an anthropological approach should be taken to identify all the facets involved.

\section{Ethical Approval}

This quantitative survey did not require approval by an ethical committee in France (L 1121-1 of French Public Health Code) and it conformed to French professional practice (R 4127 of the French Public Health Code).

\section{Conflict of Interest}

None.

\section{Acknowledgements}

The French Family Physician Teaching College of Lyon (CLGE) for supporting this work.

\section{References}

[1] Burston, G.R. (1975) Granny Battering. British Medical Journal, 3, 592. http://dx.doi.org/10.1136/bmj.3.5983.592-a

[2] Baker, A.A. (1977) Granny Battering. Nursing Mirror and Midwives Journal, 144, 65-66.

[3] World Health Organization (2002) World Report on Violence and Health. Geneva.

[4] The National Elder Abuse Incidence Study (NEAIS) (1998) Final Report. The National Center on Elder Abuse at the American Public Human Services Association. American Public Health Services Assocication, Washington DC.

[5] Fulmer, T., Guadagno, L., Connolly, M.T., et al. (2004) Progress in Elder Abuse Screening and Assessment Instruments. Journal of the American Geriatrics Society, 52, 297-304. http://dx.doi.org/10.1111/j.1532-5415.2004.52074.X

[6] Wagenaar, D.B., Rosenbaum, R., Page, C. and Herman, S. (2010) Primary Care Physicians and Elder Abuse: Current Attitudes and Practices. The Journal of the American Osteopathic Association, 110, 703-711.

[7] Pillemer, K. and Finkelhor, D. (1988) The Prevalence of Elder Abuse: A Random Sample Survey. Gerontologist, 28, 51-57. http://dx.doi.org/10.1093/geront/28.1.51

[8] Garre-Olmo, J., et al. (2009) Prevalence and Risk Factors of Suspected Elder Abuse Subtypes in People Aged 75 and Older. Journal of the American Geriatrics Society, 57, 815-822. http://dx.doi.org/10.1111/j.1532-5415.2009.02221.x

[9] INSEE (2012) French National Institute of Statistics and Economic Studies.

[10] Lachs, M.S. and Pillemer, K. (2004) Elder Abuse. Lancet, 364, 1263-1272. http://dx.doi.org/10.1016/S0140-6736(04)17144-4

[11] Lachs, M.S., Williams, C.S., O’Brien, S., et al. (1997) ED Use by Older Victims of Family Violence. Annals of Emergency Medicine, 30, 448-454. http://dx.doi.org/10.1016/S0196-0644(97)70003-9

[12] Clark-Daniels, C.L., Daniels, R.S. and Baumhover, L.A. (1990) Abuse and Neglect of the Elderly: Are Emergency Staff Aware of Mandatory Reporting Laws Department? Annals of Emergency Medicine, 19, 970-977. 
http://dx.doi.org/10.1016/S0196-0644(05)82556-9

[13] Barer, B.M. (1997) The Secret Shame of the Very Old: “I've Never Told This to Anyone Else. Journal of Mental Health and Aging, 3, 365-375.

[14] Rodriguez, M.A., Wallace, S.P., Woolf, N.H., et al. (2006) Mandatory Reporting of Elder Abuse: Between a Rock and a Hard Spot. The Annals of Family Medicine, 4, 403-409. http://dx.doi.org/10.1370/afm.575

[15] Biostat, T.G.V. (2013) Online Software-UMR 707-University of Paris 6.

[16] Collins, K.A. (2006) Elder Maltreatment. Archives of Pathology \& Laboratory Medicine, 130, 1290-1296.

[17] Rodriguez, M.A., Craig, A.M., Mooney, D.R. and Bauer, H.M. (1998) Patient Attitudes about Mandatory Reporting of Domestic Violence. Implications for Health Care Professionals. West Journal of Medicine, 169, 337-341.

[18] Kennedy, R.D. (2005) Elder Abuse and Neglect: The Experience, Knowledge, and Attitudes of Primary Care Physicians. Family Medicine, 37, 481-485.

[19] Kurrle, S.E., Sadler, P.M. and Cameron, I.D. (1992) Patterns of Elder Abuse. Medical Journal, 157, 673-676.

[20] National Council of the College of Physicians (2011) Medical Demography Wide Living Areas in the Rhône-Alpes Region.

[21] National Council of the College of Physicians (2012) Atlas of Medical Demography in France: Situation on January 2012 the 1 st. 


\section{Appendix. Anonymous Questionnary Completed Online by Family Physicians}

YOUR PROFILE ('Required)

1) What is your gender:

- $\&$ Male

- Female

2) Location:

- Rural

- Suburban

- Urban

3) Beginning of practice: *

- Less than 10 years

- 10 to 20 years

- More than 20 years

4) Office organization: *

- Team

- Individual

5) Percentage of patients over than 65 years old

- Less than $25 \%$

- Between $25 \%$ and $50 \%$

- Between $50 \%$ and $75 \%$

- More than $75 \%$

\section{Your Knowledge and Your Practice}

Non Likert Visual scale for Questions 6, 7 and 8:

\begin{tabular}{cccccc}
\hline & 1 & 2 & 3 & 4 & \\
\hline Very bad & 0 & 0 & 0 & 0 & Very good \\
\hline
\end{tabular}

6) Your recognition of clinical signs of elder abuse appears to you: *

7) Your recognition of clinical signs of psychological elder abuse appears to you *

8) Your knowledge of legislation on elder abuse appears to you

9) Have you ever suspected cases of abuse in a person over than 65 years old in your private practice?

- Never

- Once

- Between 1 to 5 times

- More than 5 times

10) If yes, have you ever reported cases of abuse in an elderly person in your private practice?

- 1 Never

- Once

- Between 1 to 5 times

- More than 5 times

11) What type of abuse you suspect him? Several options are available:

- $\Gamma$ Physical violence

- $\Gamma$ Psychological abuse 
- $\Gamma$ Neglect

- $\Gamma$ Sexual Abuse

- $\Gamma$ Other:

12) What's warning you: Several options are available

- $\Gamma$ The words or attitude of the elderly

- $\Gamma$ The words and attitudes around

- $\Gamma$ The involvement of a relative

- $\Gamma$ Call of a caregiver

13) What was your attitude with it? Several options are available

- $\Gamma$ Dialogue with relatives and/or caregivers

- $\Gamma$ Hospitalization for the elderly to avoid risk

- $\Gamma$ Reporting (administrative or judicial)

- $\Gamma \quad$ Use an institution (College of Physicians, Association)

14) Faced with a problem of abuse, do you think that the professional secret could be an obstacle to reporting?*

\begin{tabular}{lllll} 
& 1 & 2 & 3 & 4 \\
\hline Never & 0 & 0 & 0 & Always \\
\hline
\end{tabular}

15) What might help you report, it would be (multiple choice)*:

- $\Gamma$ A clear system for a smooth reporting

- $\Gamma$ Better training

- $\Gamma$ People with whom dialogue is possible

- $\Gamma$ Better information

- $\Gamma$ insurance act without risking yourself problems 